\title{
The Dark Sides of Public Service Motivation: A Multi-level Theoretical Framework
}

\section{Carina Schott, Adrian Ritz}

\author{
University of Bern \\ Address correspondence to the author at carina.schott@kpm.unibe.ch.
}

\begin{abstract}
Over the past decade, research on public service motivation (PSM) has made substantial progress in terms of explaining the desired work outcomes of the concept such as individual performance and satisfaction. In light of Perry and Wise's warning, already voiced in 1990, that high levels of PSM may produce negative outcomes, we find it all the more surprising that there is only a small albeit growing body of research on its potential "dark sides." We address this void by proposing a theoretical framework explicating the mechanisms underlying the relationships between PSM and its potential dark sides at individual and organizational levels of analysis. We also offer a number of propositions referring to different parts of our conceptual framework that provide directions for future research and should lead to a more complete understanding of PSM.
\end{abstract}

\section{INTRODUCTION}

In the more than 30 years since Rainey laid the foundation for the concept of public service motivation (PSM) by asking a large sample of private and public managers to rate their desire "to engage in meaningful public service" (Rainey 1982, 288), research on PSM has increased immensely and still continues to grow (Ritz et al. 2016). Scholars have contributed to our knowledge of especially the positive outcomes of PSM, such as job satisfaction, individual performance, and organizational commitment. In line with Perry and Wise's warning that "in some instances, public service motivation, by inducing high levels of commitment, may produce negative outcomes" (p. 371) we are wondering whether PSM is as "bright" as is generally accepted. Public service jobs such as teaching and nursing, which attract public-service motivated individuals, are often associated with stress and burnout, civil servants are frequently said to be rigid rule followers, and sometimes we realize with dismay that the people we admire for their contributions to society have engaged in unethical behavior. To this day, there has been only a small though growing body of research on the potential "dark sides" of PSM (e.g., Giauque et al. 2012b; Gould-William, Mostafa and Bottomly 2013). This study aims to enrich our knowledge about the relationship between PSM and its negative consequences, by synthesizing the limited and fragmented literature on this relationship and integrating it with theories from different disciplines, in order to form a deeper understanding and more coherent picture of the concept of PSM.

The small number of studies on the negative outcomes of PSM primarily rely on the person-environment fit (P-E fit) theory, that is, the argument that a misfit between public-service motivated people and their work environment results in negative outcomes. When people do not have the chance to act upon their PSM in practice, for example due to red tape and/or a low societal impact of their job, they are likely to experience negative attitudes (e.g., Giauque et al. 2012b; Van Loon et al. 2015). Interestingly, the question of how a P-E misfit is associated with negative attitudes has only received very little attention in the studies mentioned above.

On the basis of the Attraction-Selection-Attrition (ASA) Model (Schneider et al. 1998) we argue that it 
is not only the P-E misfit, but also fit involving PSM that can result in dark sides of PSM that have not yet been discussed in the literature. Increased homogeneity resulting from P-E fit can be a bad thing for organizations, because it is accompanied by inflexibility when the environment changes. Highly public-service motivated individuals working in homogeneous groups may cling to their regime and its values, and may resist change efforts. This means that we need to consider the possibility that PSM may not only have negative consequences for the individual but also for employing organizations.

Next to this, we argue that it is important to increase our knowledge of potential negative behavioral outcomes of PSM. For example, PSM may provoke "unethical and illegal behavior" since too strong commitment to the PSM dimension "compassion" may be in conflict with the public servant's neutrality and respect for the principles of equity and lawfulness (Maesschalck et al. 2008). Such behavior is highly negative for organizations as it can lead to inconsistencies in organizational treatment of individual cases.

The key theoretical contribution of this article will be that it sheds new light on a core concept of Public Management research: PSM. By integrating PSM with theories from psychology, sociology, and organizational ethics we explain why PSM is not uniformly beneficial. It is particularly answers to the questions what are potential dark sides of PSM, for whom they are actually "dark," and how they are associated with PSM that allow for a more complete understanding of the concept of PSM, and thereby open new research avenues with respect to negative outcomes.

In this article we first introduce PSM and provide an overview of previous research on the dark sides of PSM. After that we turn to a diverse body of research that provides the theoretical basis for our analysis of the issues at hand. We elaborate on the key aspects of a number of sociological and psychological theories that help to better understand the mechanisms underlying the link between PSM and its potential dark sides, establish that PSM may be "dark" at one level of analysis but "bright" at another, and present a number of propositions as the basis for our conceptual model to guide future research.

\section{BACKGROUND}

\section{A Rosy View on PSM: What is PSM and What is Good About It?}

Perry and Wise $(1990,368)$ were the first to formally coin the concept of PSM as "an individual's predisposition to respond to motives grounded primarily or uniquely in public institutions and organizations." Although this definition is still widely used, it has been modified by others (e.g., Brewer and Selden 1998; Rainey and Steinbauer 1999; Vandenabeele 2007). Following Schott et al. (2017), we view PSM “as a mix of normative, affective, and rational motives that triggers the desire to expend effort to benefit society at large and the public interest," because this definition (a) sets out boundaries with regard to related concepts such as user orientation and altruism, and (b) is clear about the unifying element in all commonly used PSM definitions: the willingness to do good for society and serve the public interest.

PSM is a multidimensional concept consisting of the four dimensions of (1) "self-sacrifice" (SS), (2) "compassion" (COM), (3) "attraction to public service" (APS), and (4) "commitment to public values" (CPV) (Kim et al. 2013). The latter three can be linked to affective, rational, and affective motives, respectively (Perry and Wise 1990). COM specifically describes the degree to which participants identify with the needs and suffering of others. The willingness to substitute services to others for personal rewards refers to the SS dimension. APS focuses on the extent to which participants are dedicated to public service, community, and the common good, and CPI assesses the "extent to which an individual's interest in public service is driven by their internalization of and interest in pursuing commonly held public values such as equity, concern for future generations, accountability and ethics" (Kim et al. 2013, 83).

Some authors have recommended analyzing the subdimensions of PSM separately, since relationships with other variables have been found to vary in strength and direction (e.g., Andersen and Serritzlew 2012; Giauque et al. 2012b; Jensen and Vestergaard 2016). Thus, we should think about the effects of each PSM dimension separately, and be aware of the possibility that opposing effects can cancel each other out if PSM is treated as a one-dimensional concept. In order to reduce the level of complexity in this study, however, we decided not to offer a systematic discussion of the role of each PSM dimension. Instead, we will only discuss dimensional aspects if we expect a specific PSM dimension (or more than one) to be particularly relevant within a specific context, and/or the effects of two PSM dimensions are expected to be opposing. In all other circumstances we will refer to PSM as a unidimensional concept.

The growing interest in and rosy view of PSM over the last 30 years is likely to be grounded in one of the core assumptions about PSM, that is, that "in public service organizations, PSM is positively related to individual performance" (Perry and Wise 1990, 370). Individuals scoring high on PSM are expected to perform well, as they are working to provide services they perceive as meaningful (Perry and Wise 1990; Petrovsky and Ritz 2014; Wright and Grant 2010). This 
assumption is largely supported by empirical research. Aggregated results suggest that PSM tends to be positively associated with individual and organizational performance (Ritz et al. 2016). Thus, PSM seems to be a promising concept if we want to identify predictable links between what drives employees and organizational outcomes in times of reduced financial resources (Kickert 2012) and high levels of workload, caused for instance by New Public Management regimes, which imply "even greater obligations for routine administration, monitoring and communication" (Butterfield, Edwards, and Woodall 2005, 338).

\section{Why PSM Cannot Ultimately Deliver on its Promise}

The idea that some individuals are driven by the desire to contribute to the public interest and to serve society at large has been a key concern in the academic debate for a long time (Horton 2008). The assumption that public-service motivated individuals form an important part of the people who contribute to the public interest and do good for society is reflected in Perry and Hondeghem's $(2008,8)$ claim that "if public servants are general altruists, then we will be inclined to rely on them to do good at all times." The focus on doing good for society at large sets PSM apart from the concept of user-orientation, which is directed at doing good for individual service recipients (Andersen, Pallesen and Salomonsen 2013; Jensen and Andersen 2015). Even though we like the idea that PSM may be associated with something as big as the public interest and the welfare of society, we think that Perry and Hondeghem's claim is problematic: there seems to be no consensus on what is good and desirable for society at large. According to Gailmard $(2010,38)$, for example, individuals scoring high on PSM "bring to the table their own ideals and conceptions of good public policy and the appropriate means to peruse socially desirable results." Similarly, Rainey $(1982,298)$ points out that "there are as many ways to conceive of the public service as there are to conceive of the public interest" and Andersen et al. (2013) argue that we need concrete values in order to understand what looking after the public interest implies. Schott et al. (2015) go a step further and argue that the meaning of "the public interest" is context-specific, and therefore suggest viewing the public interest as a role-dependent concept.

Arguments for the imperfect relationship between PSM and the public interest can also be found outside the field of public administration. The moral psychologists Graham et al. (2011), for example, found that different people, all believing they have high moral standards, support different political outlooks and behaviors. In the field of philosophy, Sen (2010) demonstrates by means of a simple story of three children arguing about a flute that there is not one "just society" but that there are several valid reasons of justice rivaling each other.

Together these papers suggest that the intentions to do good for society and to contribute to the public interest, which are inherent aspects of PSM, are insufficient to ensure good results at all times and for everybody. Put differently, they explain why PSM ultimately cannot deliver on its promise. Since the answer to the question of what constitutes the public interest is in the eye of the beholder " moral virtue which cannot in peculiar circumstances have patently evil results" (Bailey 1964, 237). On the basis of this line of reasoning we argue that dark sides of PSM can emerge at three different levels of analysis: individual, organizational, and societal. Put differently, the intention to do good can be at the expense of personal well-being, of the employing organization, and even of the welfare of society. However, as the discussion on the relationship between PSM and its dark sides at a societal level is rather of a philosophical nature we will for the remainder of this article focus on the dark sides of PSM at the organizational and individual levels. In the next section we will review the small yet growing body of research on the darker sides of PSM.

\section{The Darker Sides of PSM in Research}

In contrast to the large body of research on the bright sides of PSM, as far as we know only nine empirical studies have investigated its potential dark sides. In this section we will discuss these studies and point to persisting gaps in our knowledge of the topic.

Empirical research on the potential dark sides of PSM did not start until 2012, when Giauque et al. (2012b) expected and found empirical support that the PSM dimensions COM and SS foster resigned satisfaction, whereas the dimensions APM and CPI reduce resigned satisfaction. Next to this, PSM as an overarching concept has been found to be positively related to stress (Giauque at al. 2012a; Gould-Williams et al. 2013); burnout and job dissatisfaction (Van Loon et al. 2015); involuntary or long-term absenteeism (Koumenta 2015); presentism-people going to work even on days when they feel ill (Andersen et al. 2016), and negatively to physical well-being (Liu, Yang, and Yu 2015); and to exacerbate the negative effect of red tape on turnover intention and withdrawal behavior through resigned satisfaction (Quratulain and Kahn 2015). Table 1 summarizes the key findings and theoretical lenses used in these studies.

1 Although well supported in the literature, this view on the public interest is not undisputed. A contrasting voice is that of Bozeman (2007), who argues that it is not appropriate to talk about "group" or "individual" public interest, because the concept is directed at the collective good. 
Table 1. Empirical Studies on the Dark Sides of PSM (1990-2016)

\begin{tabular}{|c|c|c|}
\hline Author(s) (Year) & Theoretical Lens & Findings \\
\hline $\begin{array}{l}\text { Giauque, Ritz, Varone, } \\
\text { and Anderfuhren-Biget } \\
\text { (2012b) }\end{array}$ & P-E fit, cognitive coping & $\begin{array}{l}\text { The PSM dimensions COM and SS are positively, and the } \\
\text { dimensions CPI and APM are negatively associated with } \\
\text { resigned satisfaction. The effect of red tape on resigned } \\
\text { satisfaction becomes positive when CPI is included as a } \\
\text { moderator variable. }\end{array}$ \\
\hline $\begin{array}{l}\text { Giauque, Anderfuhren- } \\
\text { Biget and Varone } \\
\text { (2012a) }\end{array}$ & P-E fit, job demands-resources model & PSM is positively associated with stress. \\
\hline $\begin{array}{l}\text { Quratulain and Kahn } \\
\text { (2015) }\end{array}$ & $\begin{array}{l}\text { P-E fit equity theory, psychological } \\
\text { contract theory, job demands- } \\
\text { resources model }\end{array}$ & $\begin{array}{l}\text { PSM exacerbates the relationship between red tape and } \\
\text { turnover intentions, withdrawal behavior, and stress, } \\
\text { which is mediated by resigned satisfaction. }\end{array}$ \\
\hline $\begin{array}{l}\text { Gould-Williams, Mostafa } \\
\text { and Bottomley (2013) }\end{array}$ & P-E fit, motivation-hygiene theory & $\begin{array}{l}\text { PSM is positively associated with person-organization- } \\
\text { fit, with in turn has a negative association with stress and } \\
\text { intentions to quit. PSM has also a weakly positive, direct } \\
\text { relationship with stress. }\end{array}$ \\
\hline $\begin{array}{l}\text { Liu, Yang, and Yu } \\
\text { (2015) }\end{array}$ & Motivational self-regulation theory & $\begin{array}{l}\text { Higher levels of PSM are associated with higher mental } \\
\text { wellbeing but lower physical wellbeing. }\end{array}$ \\
\hline $\begin{array}{l}\text { Hamann and Foster } \\
\text { (2014) }\end{array}$ & Job demands-control-support model & $\begin{array}{l}\text { Public employees perceive higher levels of stress than } \\
\text { private sector employees }\end{array}$ \\
\hline $\begin{array}{l}\text { Van Loon, Vandenabeele, } \\
\text { and Leisink (2015) }\end{array}$ & P-E fit, institutional theory & $\begin{array}{l}\text { The type of organization and the societal impact potential } \\
\text { of the work moderate the relationship between PSM and } \\
\text { burnout and dissatisfaction. }\end{array}$ \\
\hline Koumenta (2015) & P-E fit & $\begin{array}{l}\text { There is a positive association between PSM and } \\
\text { involuntary or long-term absenteeism. }\end{array}$ \\
\hline $\begin{array}{l}\text { Andersen, Holten, and } \\
\text { Jensen (2016) }\end{array}$ & & $\begin{array}{l}\text { There is a positive association between PSM and } \\
\text { presentism. }\end{array}$ \\
\hline
\end{tabular}

What unifies almost all studies is that they rely on the idea of the P-E misfit (Kristof 1996) to explain negative attitudinal outcomes of PSM. A central argument of this theory is that an incompatibility between the characteristics of an individual and his/her work environment can cause negative effects. Kristof (1996) differentiate between various types of P-E misfit; types that are used in studies on the dark sides of PSM are "person-organization" and "person-job" misfit. The authors further argue that misfit can be either complementary or supplementary. Complementary misfit occurs when individuals' characteristics or abilities do not fill a gap in the current environment (demandsability misfit), or when individuals' needs are not met by the environment (needs-supplies misfit). Supplementary misfit exists when an individual experiences the values of the employing organization as dissimilar from his/her personal values.

With regard to research on PSM this means that if individuals cannot fulfill their desire to serve the public interest due to environmental burdens and constraints (needs-supplies misfit) or experience the values of the employing organization as dissimilar to their own personal values (supplementary misfit), this is likely to negatively affect their attitudes. Interestingly, except for the study by Gould-William et al. (2013) researchers do not directly measure the fit between the individual and the environment, but use it as a means to explain their findings. For instance, Van Loon et al. (2015) found that the relationship between PSM and dissatisfaction depends on the societal impact of the work. Quratulain and Kahn (2015) found evidence that individuals scoring high on PSM are more likely to experience increased levels of intentions to quit their job, resignation, withdrawal, and stress, because they feel incongruent with the values of their organization if there is much red tape. Koumenta (2015) argues that highly public-service motivated individuals may suffer due an inability to deliver outcomes that matter to them. Because of the discrepancy between what they think should be an outcome of their work and actual work outcomes, the risk of long-term absenteeism can increase.

Giauque et al. (2012a), Gould-Williams et al. (2013), and Hamann and Foster (2014) discuss an alternative type of P-E misfit as an explanation for the relationship between PSM and stress. They argue that stress may be explained by highly public-service motivated individuals displaying high expectations with regard to their job, and consequentially suffering from stress if they perceive an inability to meet their high performance standards. The problem here is not that individuals' characteristics or abilities do not fill a gap in their work environment; rather, stress seems to result from 
the fact that individuals cannot meet the high demands they have set themselves.

When we review the literature on the dark sides of PSM we note three gaps in knowledge. First, even though most studies rely on the P-E misfit to explain negative attitudinal outcomes of PSM, scholars do not pay a great deal of attention to the question as to how the P-E misfit is associated with negative attitudes. Put differently, we know little about the causal mechanisms underlying the relationships between PSM, P-E misfit, and negative attitudinal outcomes. This observation is consistent with the recent call for understanding the psychological mechanism through which person-organization misfit leads to employees' intentions to quit their job (Jin, McDonald and Park 2016; Peng, Lee and Tseng 2014). Second, there has been insufficient research in to the possibility that $P-E$ fit (not P-E misfit) involving PSM can, in some instances, also lead to negative outcomes. As suggested by the ASA Model, P-E fit fosters homogeneity within groups and is often associated with individuals' inability to react to environmental changes. Third, our literature review reveals a lack of attention to negative behavioral outcomes that can result from high levels of PSM. The extra-organizational focus of PSM may be in conflict with the organization's interests, and this may result not only in frustration but also in unethical behavior (Maesschalck et al. 2008; Steen and Rutgers 2011).

\section{APPROACHES TO A THEORY OF THE DARK SIDES OF PSM}

In order to fill the knowledge gaps identified in the previous section and gain a more complete understanding of the dark sides of PSM, we introduce different theories from psychology, sociology, and organizational ethics literature and integrate them with PSM theory. We start with identity theory and psychological contract theory, as two theories that provide insights into the mechanisms underlying the relationship between PSM and negative attitudinal outcomes resulting from the often cited P-E misfit. After that, we use insights from the ASA model to increase our knowledge of the effect of P-E fit involving PSM on possible negative outcomes at different levels of analysis. Finally, literature on noble course corruption and moral disengagement is integrated with PSM theory to gain a better understanding of PSM and its negative behavioral consequences.

\section{Mechanisms Explaining Negative Attitudes From a P-E Misfit Perspective \\ Insights From Identity Theory \\ We argue that insights from identity theory help explain how a complementary P-E misfit leads to}

negative attitudes, and why highly public-service motivated individuals experience negative attitudes if they feel that their jobs do not allow them to contribute to society. A central concept in this sociological theory is the self, which is assumed to emerge out of the interaction with society (Burke and Stets 2009; Stryker and Burke 2000). The self consists of a collection of different identities, each of which is based on the individual occupying a particular role in society: friend, man or woman, professional, public servant, etc. PSM has also been called an "identity": a public service identity (Perry and Vandenabeele 2008; Vandenabeele 2007). By means of socialization, social identification, cultural preferences, and social learning, public-institutional logics are transmitted and individuals are expected to "acquire a new social identity as member of the institution" (Perry and Vandenabeele 2008:60).

Within a control system identities are preserved by a process called identity verification (Burke and Stets 2009). This means that we engage in activities that strengthen the set of meanings (identity standards) we hold for ourselves in a particular role if we perceive our behavior to deviate from these standards. What follows is that "one of the consequences of high levels of commitment to an identity is that people will work harder to maintain reflected [self-] appraisals (input) consistent with their identities. Individuals with low commitment to an identity will not work as hard to maintain congruence" (Burke and Reitzes 1991, 224). These high levels of commitment to a specific identity can be negative for individuals, because the strong desire to reduce the non-correspondence between input and identity standard outplays rational considerations (e.g., Burke and Stets 2009; Stets and Serpe 2013), thereby preventing individuals from adjusting their efforts on the basis of the expected chance to reach this congruence.

With regard to PSM (or public service identity) and situations of P-E misfit this means that the more strongly people are committed to serve the public interest, the more effort they should invest if they perceive that their role performance is blocked by difficulties (e.g., low societal impact of the work, red tape, etc.) in order to maintain the desired identity standard related to their public service identity. By making the perceived meaning about themselves in difficult situations correspond to the meaning of the (public service) identity standard, people verify who they are as public-service motivated individuals. If despite extra efforts highly public-service motivated individuals are prevented from closing the gap between the perception of their role performance and their identity standard-that is, if they are prevented from verifying their public service identity-they are likely to become over-engaged and 
experience negative feelings such as stress, ${ }^{2}$ burnout, and the intention to leave (Burke and Stets 2009). This leads to our first proposition.

\section{Proposition 1: The greater individuals' PSM, the harder they will work in situations in which, in an attempt to verify their identities, they perceive their role performance to deviate from their public service identity standards, and this leads to over- engagement, stress, burnout, and intentions to quit their job.}

However, as mentioned above, we also need to consider the possibility that one (or more) PSM dimensions may be particularly relevant for this proposition. Research on compassion fatigue suggests that if people identify too strongly with the beneficiaries of their work, they are more likely to experience stress and anxiety (Grant and Schwarz 2011). According to Klimecki and Singer (2012), this is the result of the exposure to the suffering of others and the inability to help. On the basis of this we argue that the PSM dimension of "compassion," which "captures the emotional state of empathy and identification with specific unprivileged or weak groups" (Jensen and Vestergaard 2016) is likely to play a stronger role in Proposition 1 than do the other three PSM dimensions.

\section{Insights From Psychological Contract Theory}

Next to identity theory, insights from psychological contract theory are useful to increase our understanding of the relationship between P-E misfit involving PSM and negative attitudes (Giauque et al. 2012b; Quratulain and Kahn 2015). Even though somewhat challenging to define, it is generally accepted that the psychological contract refers to an individual's subjective beliefs, shaped by the organization, regarding the terms of an exchange relationship between the employee and the employing organization (Rousseau 1995). It is expected to represent a mental schema that is relatively stable over time.

A key feature of any psychological contract is the idea of mutuality. By interacting with employees and observing organizational rules and procedures, employees develop beliefs about what they owe to their employer as well as how the organization is obligated to reciprocate their efforts (Rousseau and Parks 1993).

2 It should be noted that the type of stress we are referring to is role stress. People experience stress because they are unable to verify the roles they hold in society. This type of stress is different from challengebased stress, which in a meta-analytic regression (Podsakoff, LePine, and LePine 2007) has been found to be positively associated with performance (LePine et al. 2005) and negatively with intentions to quit one's job.
The problem, however, is that there is no guarantee that organizations and/or employees are always able and/or willing to fulfill all mutual obligations, which results in a breach of psychological contract. One consequence of such a breach initiated by the employing organization can be "resigned satisfaction" (Giauque et al. 2012 b). When employees' expectations are incompatible with the working environment-that is, when they are not able to contribute to society at large due to, for example, procedural constrains or a high workloadthey feel that the reciprocal exchange agreement (psychological contract) is violated, and consequently cope passively by reducing "their personal expectations in order to reach a new equilibrium in their employment relationship" (Giauque et al. 2012b, 188). In other words, "modifying input" seems to be a strategy that helps to lessen the tensions experienced in situations of $\mathrm{P}-\mathrm{E}$ incongruence, resulting in the employee's acceptation of the situation (Adams 1963).

Others have argued that psychological contracts present the foundation for perceptions of control and predictability for employees, which decrease when obligations associated with psychological contracts are not met (Shore and Tetrick 1994; Tetrick and LaRocco 1987). This loss of control and predictability, in turn, may lead to the employees' experiencing work-related stress (e.g., Maslach, Schaufeli, and Leiter 2001; Shore and Tetrick 1994) and intentions to quit their job (for more information, see the meta-analysis by Zhao et al. 2007). The reason for this is that uncertainty undermines direct or problem-focused coping strategies, because the source of the events cannot be detected and controlled (Miller 1987). This inability to deal with events actively, and instead rely on passive coping strategies such as avoidance or restricting one's expectations (Cronkite and Moos 1984; Menaghan and Merves 1984), is very unfortunate because it increases anticipatory anxiety and stimulates a state of unresolved fear and stress (Epstein 1972; Lazarus 1966). For PSM this implies that employees experience a loss of control and predictability if-against expectations-they are not able to fulfill their need for serving the public interest. Because this breach of psychological contract cannot be controlled by individuals, they are likely to fall back on passive coping strategies such as avoidance or selective ignoring (rather than active, problem-focused strategies), which have been found to be related to stress and the intention to quit the job. This leads to our second proposition.

Proposition 2: If highly public-service motivated
individuals are prevented from
acting upon their PSM in prac-
tice, they are likely to experience
abreach of psychological contract
and consequentially engage in


passive coping strategies, which have been found to be related to stress, burnout, resigned satisfaction, and intentions to quit the job.

This means that stress, burnout, and intentions to quit can be explained by two different mechanisms: identity verification (P1), and the use of passive coping strategies (P2). In contrast, resigned satisfaction and overengagement can only be explained by one of the two mechanisms of passive coping strategies and identity verification, respectively.

When looking at the four different dimensions of PSM separately, we may argue that the dimension "CPV" may play a stronger role in this proposition than do the other three PSM dimensions. According to Jensen and Vestergaard (2016) this dimension reflects a motivation to advance the interest of society at large. Since the realization of this goal seems to be much more difficult than benefitting weak or underprivileged groups (the motive for COM) and participation in public services (the motive for APS), we argue that individuals with high levels of CPV are particularly likely to experience a breach of psychological contract and consequentially engage in passive coping strategies, which have been found to be associated with negative attitudes.

\section{Going Beyond the Individual Level}

Attitudes such as stress, burnout, and the intention to quit one's job resulting from the P-E misfit involving PSM can negatively affect not only public-service motivated individuals themselves, but also organizations and clients, because these attitudes are often associated with absenteeism (Hackett et al. 1996) and unauthorized breaks, which in turn can negatively affect the quality and quantity of public services (Hanisch 2002). It is particularly higher levels of stress that have been found to contribute to undermining the efficiency and effectiveness of public sector organizations $(\mathrm{McHugh}$ and Brennan 1994).

The attitude of "resigned satisfaction," which results from the use of passive coping strategies as a consequence of a P-E misfit as described in Proposition 2, differs from stress, burnout, and the intention to quit in the sense that the first attitude is not necessarily negative for the individuals themselves, whereas the last three are. Resigned satisfaction implies that employees do not care about their work but are satisfied. In contrast, employees who experience stress and intend to quit are likely to feel dissatisfied with their work. It should be noted that we do not expect this difference to be reflected in the relationships between these attitudes and the consequences for employing organizations and clients. As described above, stress, burnout, and intentions to quit tend to be negatively associated with the quality and quantity of organizational performance. The same is likely to apply to the relationship between resigned satisfaction and organizational outcomes. If employees do not care about their work and lower their aspiration levels, they are unlikely to make a big effort in terms of the quality and quantity of their service delivery.

Finally, the attitude of "overengagement," resulting from the failed attempt to verify one's public service identity as described in Proposition 1, may have positive short-term consequences for organizations but negative ones for the public-service motivated individuals themselves. We argue that highly engaged employees are likely to be willing to work overtime and to take on additional tasks, which is in line with the finding that overengagement is associated with presentism (Hansen et al. 2008). This is a positive thing for both clients and the organization in the shortrun, as the quality and quantity of public service provision improves temporarily. On an individual level, however, overcommitment has been found to be a very strong predictor of work-life conflict (Kinman and Jones 2008). Work-life conflicts may take several forms, but the one resulting from excess time devoted to work is thought to be of key importance (Netemeyer 1996). Obviously, in the long run, too, negative effects can be expected for the organization and clients. If employees are overengaged for a longer period, they are likely to burn out and as a result deliver lower-quality work, thereby negatively affecting the quality of the organization's service provision. This leads to our third proposition.

\section{Proposition 3: The relationship between PSM and a reduced quality and quan- tity of an organization's public service delivery is mediated by the attitudes of resigned satisfaction, burnout, stress, and intentions to quit, as well as overengagement in the long-run.}

\section{Mechanisms Explaining Negative Attitudes From a P-E Fit Perspective}

Insights From the ASA Model

On the basis of insights from the ASA model, we argue that it is not only P-E incongruence involving PSM, but also P-E congruence that in some instances can lead to negative outcomes for organizations, clients, and individuals, outcomes which have not yet been studied. The ASA model proposes that "the outcome of three interrelated dynamic processes, attractionselection-attrition, determines the kind of people in an organization, which consequentially defines the nature of an organization, its structure, processes and culture" (Schneider et al. 1995, 748). This means that 
the theory provides an explanation for the interplay between negative individual- and organizational-level effects resulting from P-E fit. People are attracted by an organization on the basis of a good fit, and are selected if they suit the organization. The process of attrition refers to the idea that employees leave the organization if they do not fit. As a result of these three processes homogeneity is predicted to increase over time. This hypothesis has been validated by a large body of empirical research (e.g., De Cooman et al. 2009, Schneider et al. 1995). Interestingly, and contrary to the prediction of the P-E fit hypothesis that a good fit results in only positive outcomes, the ASA model predicts that increased homogeneity is associated with both negative and positive outcomes (Schneider et al. 1995). In particular, Schneider et al. (1995) warn of insensitivity and the inability of employees to react to environmental changes. Support for the negative outcomes of homogeneity also comes from research on diversity. From this perspective, heterogeneous groups have been found to prevent premature decision-making on issues that require careful consideration (Van Knippenberg et al. 2004). "If all [group] members are alike, [in contrast], they may have little to talk about, they may compete with each other, or they may all commit the same mistake" (Shepard 1968, 118), and can be associated with complacency (Jehn, Chadwick, and Thatcher 1997). An explanation for the relationship between homogeneity and negative outcomes is provided by the process of "groupthink," that is, the "excessive tendency to seek congruence among group members" while losing perspective (Brehm et al. 2005).

For research on PSM this may imply that individuals belonging to homogeneous groups of highly publicservice motivated people are likely to be blindly loyal to the regime and its values. Because of groupthinkthe priority of agreement and harmony among group members over critical evaluation-resulting from P-E congruence (not incongruence) and homogeneity, there is a potential risk that individuals are inflexible regarding environmental changes and the needs of different groups of stakeholders. This can be problematic. If all employees rely on similar values and have similar political attitudes regarding PSM, there is a risk that employees fail to be responsive to all people they serve or to be more loyal to some political leaders than others (Prebble 2016). This leads to our fourth proposition.

\section{Proposition 4: If highly public-service motivated individuals work in homogeneous groups, they are likely to engage in the process of groupthink, which leads to inflexibility and blind loy- alty to the governing coalition of the organization.}

Going Beyond the Individual Level

Interestingly, being inflexible and blindly loyal to the regime is not necessarily a bad thing for individuals. Even though ambiguity will always remain a characteristic of public sector work (cf. Maynard-Moody and Musheno 2003), previous research has shown that individuals who follow an organizational logic (i.e., organizational rules and regulations) experience work-related tensions and pressures to a lesser degree than employees who are guided by professional norms and principles (Schott et al. 2016). Rather, the effect of PSM resulting from a P-E fit (not misfit) seems to be negative for the employing organization and clients. If highly public-service motivated individuals are blindly loyal to "their" values as a result from groupthink stimulated by homogeneity/P-E fit, then non-responsive administrative cultures are a logical consequence. This is highly undesirable from a perspective of democracy theory, which emphasizes the necessity for public-sector employees to be always ready to continue a dialogue, be able to find compromises, and make reason-based decisions (Rawls 1971). Similarly, Rainey (2009) argues that responsiveness to the public's wishes and needs should be one of the core characteristics of public servants. It presents a central aspect in the performance of public sector organizations (Boyne 2002) and a key value of public organizations in general (Beck Jorgensen and Bozeman 2007).

This shows the need for a multi-level approach to the study of the dark sides of PSM. Although being inflexible and fiercely loyal to the regime is not necessarily a bad thing for public-service motivated employees themselves, it implies negative consequences at organization level. "Rigid rule following," or sticking inflexibly to the rules, has been described as a coping strategy that helps public servants to deal with demanding work circumstances (Tummers et al. 2015, 2 ). However, if employees stick to the rules and are unresponsive to citizens, the public agency as a whole will be evaluated negatively by citizens (Shingler et al. 2008). This leads to our fifth proposition:

\section{Proposition 5: The relationship between PSM and a non-responsive administrative culture is mediated by inflexibility and blind loyalty to the regime.}

\section{PSM and Negative Behavioral Consequences}

Insights From Noble Cause Corruption Literature

Next to negative attitudes such as stress, resigned satisfaction, and blind loyalty, PSM can also have undesirable behavioral outcomes. Steen and Rutgers (2011) warn that the extra-organizational focus of PSM may be in conflict with the organization's interests, and that this may result in unethical behavior. Too strong 
a commitment to the PSM dimension of "compassion" may conflict with a public servant's neutrality and respect for the principles of equity and lawfulness, which in turn may provoke unethical behavior (Maesschalck et al. 2008). In line with this DeHart-Davis (2007, $895)$ argues that "commitment to public service may influence rule bending by inspiring employees to go above and beyond the call of duty - including bending rules - in order to further the public interest." Numerous definitions of unethical behavior can be found in the literature (Jones 1991), but in this study we focus on deviant behaviors such as attempts to obscure the truth, rule bending or even breaking, and outright lying.

The potential risk of being strongly attached to values that in themselves are "good" has also been recognized in the literature on noble cause corruption among police officers, which can be defined as using illegal means for organizationally and socially approved ends (Punch 2000). The idea of "noble cause corruption" can be confusing, as it does not refer to corruption in the sense that an actual corrupter and direct gain are involved. Rather, it is related to the saying "the end justifies the means." For example, police officers who fight crime in the public interest have been found to bend or break the law, or to use illegal methods such as falsifying testimony, intimidating witnesses, paying informants with illegally obtained drugs, and planting evidence to reach this end (Manning 1977). A related stream of literature is that on administrative evil, which has its roots in the genocide perpetrated by Nazi Germany (Adams, Balfour, and Reed 2006). A less extreme and more recent form of the phenomenon is the torture and abuse of detainees at, for example, Abu Ghraib prison. In times of a new paradigm of war-the war on terrorism following September 11-that caused ambiguity and uncertainty about the rules of the American military, prison guards used the tacit permission available to abuse detainees "in order to help their comrades suppress a growing insurgency, find weapons of mass destruction, and prevent acts of terrorism" (Adams et al. 2006, 690).

The cognitive mechanism that helps explain the link between PSM and these unethical behaviors can be described as moral justification, which is one of the five mechanisms central to Bandura's (1999) theory of disengagement. When people call upon moral justification they frame their misbehavior as being worthy and desirable because it serves a higher social or moral purpose (Loyens 2014). In other words, highly public-service motivated individuals can exhibit unethical behaviors (e.g., rule breaking and lying), because the process of moral justification psychologically frees them to act inappropriately in order to reach the higher goal of contributing to the public interest and doing good for society. This leads to our sixth proposition.

\section{Proposition 6: The greater an individual's PSM, the more likely he or she will be to engage in the process of moral jus- tification (justifying bad means by good ends), which leads to unethi- cal behaviors such as rule bending and/or breaking.}

Looking at PSM as a multi-dimensional construct raises the question whether the sub-dimensions may have opposing effects. From research on empathy we know that empathy can come at the expense of justice (Batson et al. 1995). This implies that individuals with high levels of COM-individuals who strongly identify with specific underprivileged or weak groups-are particularly likely to behave unethically in situations in which the welfare of that group can be improved by acting unethically towards others. The same may be true for the PSM dimension of CPV, which reflects the extent to which people's interest in public service is driven by their interest in pursuing socially approved norms. In this case, it is not the welfare of weak groups of society but the desire to realize a "perfect society with corresponding values" that triggers individuals with high levels of CPV to use illegal means.

\section{Going Beyond the Individual Level}

It is interesting to note that unethical behavior such as rule breaking and/or bending resulting from high levels of PSM is not seen as particularly negative for publicservice motivated individuals themselves. Rather, this type of behavior is often described as coping behavior that helps public sector employees "to master, tolerate or reduce external and internal demands and conflicts" (Tummers et al. 2015, 2). However, deviance from rules and regulations in order to reach the higher goal of serving the public interest and contribute to society at large und ermines equal treatment, reliable public service, and fairness, which are key values of public organizations (Beck Jorgensen and Bozeman 2007). The negative consequences for public organizations of public servants deviating from rules and regulations are also discussed in public policy implementation literature. For example, Bekkers et al. (2007) point out that public professionals' unwillingness to implement public policies can negatively affect the relationship between citizens and these professionals, which may eventually damage the output legitimacy of government. In line with this, Ewalt and Jennings (2004) have argued that this unwillingness can also decrease the effectiveness of policy implementation given that committed policy implementers play a crucial role in achieving policy goals. This leads us to our seventh and final proposition. 


\section{Proposition 7: The relationship between PSM and unreliable organizational output is mediated by unethical behav- ior such as rule bending and/or breaking.}

\section{CONCLUSION: A MULTI-LEVEL FRAMEWORK FOR THE DARK SIDES OF PSM}

Our theoretical discussion of the dark sides of PSM and concluding propositions can be summarized in a multi-level framework (see the figure below, and a complementary table containing the specific dark sides of PSM at individual and organizational levels of analysis; figure 1, table 2). The conceptual framework is useful because it helps explain why public-service motivated individuals can experience negative attitudes and engage in unethical behavior, and that the concept of PSM can also be negative for organizations and clients.

Table 2 further clarifies that attitudinal and behavioral consequences of PSM do not necessarily have to be negative for the public-service motivated individual him- or herself in order to have a negative impact on the employing organization and clients, and that it is even possible that PSM is "bad" for an individual but "good" for an organization. By exploring these relationships in-depth our article aims to make two important contributions to the PSM literature, which will be discussed below.

The limited previous research on the dark sides of PSM has largely focused on the relationship between PSM and negative attitudes such as stress and resigned satisfaction, and researchers have argued that these relationships result from individuals' inability to act upon their PSM in practice (e.g., Giauque et al. 2012a, 2012b). Our study goes further than this: we provide an answer to the question of how a misfit involving PSM is associated with these negative attitudes, that is, what the underlying mechanisms are. We also show that there may be additional attitudinal dark sides of PSM that have not yet been studied, such as inflexibility and blind loyalty. These attitudes result from a P-E fit (not misfit!) involving PSM. Next to this, we elaborate on the mechanism explaining how PSM and unethical behavior are related. In doing so, we highlight the fact that negative effects of PSM may be more diverse than expected and are not only restricted to situations of P-E misfit. This implies that a broader approach is needed to fully understand what the possible individual dark sides of PSM are.

A second contribution of this article is its multi-level approach. Our conceptual model explains that the negative effects of PSM may not be restricted to individual outcomes such as stress, intentions to quit, and unethical behavior, which have been the focus of previous work (e.g., Gould-Williams et al. 2013, Steen and Rutgers 2011). Rather, they can indirectly be related to organizational-level outcomes such as low quality and quantity of public service delivery, nonresponsive administrative cultures, and unreliable service. However, this is not the complete picture. We have illustrated that the relationships between PSM and negative outcomes at individual and organizational levels are highly complex. Whereas, for instance, being highly loyal to the regime and bending rules are actually coping strategies that help individuals to manage

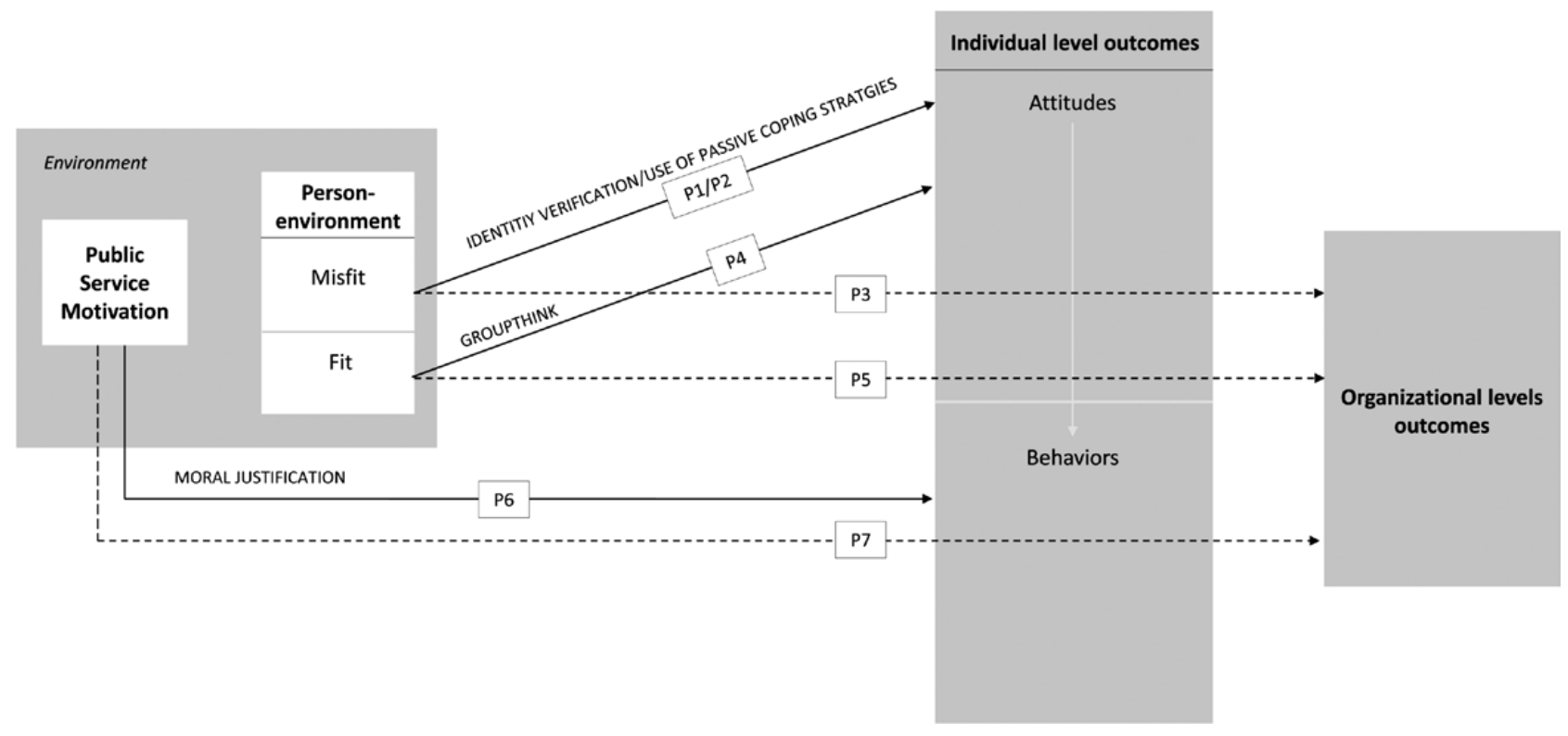

Figure 1. A Multi-levelTheoretical Framework of the Dark Sides of PSM. Note: ---> Reflects mediation hypotheses. 
Table 2. Dark Sides of PSM at Individual and Organizational Levels of Analysis

\begin{tabular}{|c|c|c|c|}
\hline \multicolumn{2}{|c|}{$\begin{array}{l}\text { Consequences for Public-service Motivated } \\
\text { Individuals }\end{array}$} & \multicolumn{2}{|c|}{ Consequences for Employing Organizations and Clients } \\
\hline Positive & Negative & Positive (Short-term) & Negative \\
\hline & Over-engagement & $\begin{array}{l}\text { Quality and quantity of } \\
\text { service delivery }\end{array}$ & \\
\hline & Stress & & $\begin{array}{l}\text { Low quality and quantity of } \\
\text { service delivery }\end{array}$ \\
\hline & Burnout & & $\begin{array}{l}\text { Low quality and quantity of } \\
\text { service delivery }\end{array}$ \\
\hline & Intentions to quit the job & & $\begin{array}{l}\text { Low quality and quantity of } \\
\text { service delivery }\end{array}$ \\
\hline Resigned satisfaction & & & $\begin{array}{l}\text { Low quality and quantity of } \\
\text { service delivery }\end{array}$ \\
\hline Blind loyalty ${ }^{\mathrm{a}}$ & Blind loyalty ${ }^{\mathrm{a}}$ & & $\begin{array}{l}\text { Nonresponsive administrative } \\
\text { culture }\end{array}$ \\
\hline Inflexibility $^{a}$ & Inflexibility ${ }^{\mathrm{a}}$ & & $\begin{array}{l}\text { Nonresponsive administrative } \\
\text { culture }\end{array}$ \\
\hline Unethical behavior $^{\mathrm{a}}$ & Unethical behavior $^{\mathrm{a}}$ & & $\begin{array}{l}\text { Unreliable service/unequal } \\
\text { treatment }\end{array}$ \\
\hline
\end{tabular}

Note: In this table, only the direct consequences of PSM for individuals are summarized. This means, we do not include absenteeism and presentism, for example, as it is a consequence of stress/burnout and over-engagement, respectively.

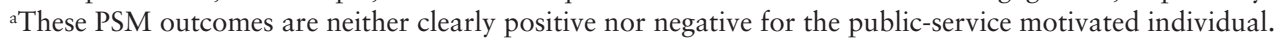

internal and external tensions (Tummers et al. 2015), and resigned satisfaction implies that employees are satisfied (Giauque et al. 2012b), the effects of these attitudes and behaviors can be rather harsh for public organizations and clients. In contrast, being overengaged as a result of the inability to act on one's PSM in practice despite major efforts is likely to be experienced as negative by individuals but as positive by the employing organization, which in the short term benefits from increased efforts. This implies that the question for whom PSM is dark is highly complex, and can only be answered by analyzing the dark sides within a multi-level perspective. PSM can have negative consequences for the public-service motivated individuals themselves and at the same time rather positive ones for the employing organization, and vice versa.

\section{Directions for Future Research}

We have offered a number of propositions referring to different parts of our theoretical framework that provide directions for future research. Although wellgrounded in various theories, the framework still needs to be investigated empirically. Obviously, these propositions are valuable only to the extent that empirical investigation is possible. We therefore encourage researchers interested in PSM to take Perry and Wise's warning (Perry and Wise 1990) about the dark sides of PSM seriously and to start conducting research not only on negative attitudes resulting from individuals' inability to act upon their PSM in practice, but also to address, for example, questions related to the negative consequences of PSM (as both a multidimensional and a one-dimensional concept) resulting from the P-E fit at an individual as well as organizational level of analysis.

Particularly, we suggest applying quantitative methods and using existing measurements to test our propositions, as there is already a large body of research and our knowledge about the various concepts and mechanism is substantial. In fact, each causal mechanism considered here in this study has been the subject of extensive research, which makes it feasible to adopt the methods used in earlier research on the dark sides of PSM. Specific suggestions regarding such adaptations are beyond the scope of this study, but we will provide some examples of empirical studies on the various concepts and mechanism we are interested in.

Moore et al. (2012), for example, recently developed a measurement instrument for employees' moral justification in the work place. In the field of psychology many validated measurement instruments on coping with stress can be found (e.g., Folkmann and Lazarus 1980; Greenglass, Schwarzer, and Taubert 1999). These scales present a useful starting point for the development of a scale assessing how individuals cope with a P-E misfit. Next to this, the literature offers a variety of measurement instruments for negative attitudinal (e.g., Bright 2008; Gould-Williams et al. 2013) and behavioral outcomes (e.g., Hassan, Wright, and Yukl 2014; Wouters et al. 2014), as well as discussions of how to measure organizational performance in such a way that the many concerns of public management, such as 
quality, quantity, and responsiveness are covered (for a review, see Andrews, Boyne, and Walker 2006). In addition to survey research, we encourage scholars to think of ways to design experimental studies on the dark sides of PSM, because survey research cannot live up to the rigor and level of control of an experimental design (Tummers et al. 2016). For example, researchers could experimentally manipulate the P-E fit and misfit. Next to this, asking randomly assigned people to either recall past incidents where they engaged in moral disengagement (treatment) or what they had done at work the previous day (control) would allow us to make causal interferences and to isolate the process of moral justification triggered by PSM when it comes to engage in unethical behavior.

We would also like to point to two practical implications of this study. First, many studies advise that job applicants' level of PSM should be considered as a selection criterion, that PSM levels should be increased in order to have a motivated and high-performance workforce, and that a public service-oriented organizational culture should be created (Ritz et al. 2016). We argue that this may be problematic, because we do not yet have a full understanding of what the dark sides of PSM for individuals themselves and for public organizations are. According to our propositions 4 and 5, value congruence as a core element of selection strategies in public organizations may not be the right approach. Therefore, we recommend reflecting on the composition of the work teams and organizations (homogeneous or heterogeneous?) before using PSM as an explicit selection criterion. Second, studies often recommend training teams and managers in public service values (Ritz et al. 2016). Such a rather isolated development strategy, however, can lead to a rather strong commitment to a public service identity, which may be problematic if the daily work situation does not allow for adequate identity verification as explained in proposition 1. We therefore suggest reconsidering the role of public value trainings while thinking about how to reduce the negative outcomes that result from unsatisfactory identity verification. Put simply, preventing from public service demotivation may be more effective than stimulating PSM.

In conclusion, in this article we have set out to show that some skepticism regarding the "rosy view" on PSM is warranted and a more balanced view is needed. Having PSM can be a "good" thing. However, there are several theoretical arguments indicating that PSM has the potential to increase negative outputs and outcomes at the individual and organizational levels. Even more, since public-service motivated individuals are driven to serve the public interest, and the question of what constitutes the public interest is in the eye of the beholder, we should be aware of the fact that the realization of PSM can be a "bad" thing.

\section{Acknowledgments}

We thank four anonymous reviewers and Kenneth Meier (editor in chief) for their helpful comments on an earlier version of this article.

\section{References}

Adams, John S. 1963. Towards an understanding of inequity. The Journal of Abnormal and Social Psychology 67:422-36.

Adams, Guy B., Danny L. Balfour, and George E. Reed. 2006. Abu Ghraib, administrative evil, and moral inversion: The value of "Putting Cruelty First". Public Administration Review 66:680-93.

Andersen, Lotte, and Søren Serritzlew. 2012. Does public service motivation affect the behavior of professionals? International Journal of Public Administration 35:19-29.

Andersen, Lotte Bøgh, Torben B. Jørgensen, Anne-Mette Kjeldsen, Lene H. Pedersen, and Karsten Vrangbæk. 2013. Public values and public service motivation: Conceptual and empirical relationships. The American Review of Public Administration 43:292-311.

Andersen, Lotte B., Thomas Pallesen, and Heidi H. Salomonsen. 2013. Doing good for ' others and/or for society? The relationships between public service motivation, user orientation and university grading. Scandinavian Journal of Public Administration 17:23-44.

Andersen, Lotte B., Ann-Loise Holten, and Ulrich T. Jensen. 2016. Explaining a Dark Side: Public Service Motivation, Absenteeism and Presentism, Paper presented at the European Group for Public Administration (EGPA) conference in Utrecht, the Netherlands, August 24-26, 2016.

Andrews, Rhys, George A. Boyne, and Richard M. Walker. 2006. Subjective and objective measures of organizational performance: an empirical exploration. In Public Service Performance: Perspectives on Measurement and Management, ed. George A. Boyne, Kenneth J. Meier, Laurence J. O’Toole Jr., and Richard M. Walker, 14-34. New York, NY: Cambridge Univ. Press.

Bailey, Stephen K. 1964. Ethics and the public service. Public Administration Review 24:234-43.

Bandura, Albert. 1999. Moral disengagement in the perpetration of inhumanities. Personality and Social Psychology Review 3:193-209.

Batson, Daniel C., Tricia R. Klein, Lori Highberger, and Laura L. Shaw. 1995. Immorality from empathy-induced altruism: When compassion and justice conflict. Journal of Personality and Social Psychology 68:1042-54.

Beck Jørgensen, Torben, and Barry Bozeman. 2007. Public values an inventory. Administration and Society 39:354-81.

Bekkers, Victor J. J. M., Geske Dijkstra, Arthur Edwards, and Menno Fenger. 2007. Governance and the democratic deficit: Assessing the democratic legitimacy of governance practices. Hampshire, UK: Ashgate Publishing, Ltd.

Boyne, George A. 2002. Public and private management: What's the difference? Journal of Management Studies 39:97-122.

Bozeman, Barry. 2007. Public Values and Public Interest: Counterbalancing Economic Individualism. Washington, DC: Georgetown Univ. Press.

Brehm, Sharon S., Saul Kassin, and Steven Fein. 2005. Social psychology, 6th ed. New York, NY: Houghton Mifflin.

Brewer, Gene A., and Sally C. Selden. 1998. Whistle blowers in the federal civil service: New evidence of the public service ethic. Journal of Public Administration Research and Theory 8:413-39.

Bright, Leonard. 2008. Does public service motivation really make a difference on the job satisfaction and turnover intentions of public employees? The American Review of Public Administration 38:149-66.

Burke, Peter J., and Donald C. Reitzes. 1991. An identity theory approach to commitment. Social Psychology Quarterly 54:239-51.

Burke, Peter J., and Jan E. Stets. 2009. Identity Theory. Oxford: Oxford Univ. Press.

Butterfield, Reginald, Christine Edwards, and Jean Woodall. 2005. The new public management and managerial roles: The case of the police sergeant. British Journal of Management 16:329-41. 
Cronkite, Ruth C., and Rudolf H. Moos. 1984. The role of predisposing and moderating factors in the stress-illness relationship. Journal of Health and Social Behavior 25:372-93.

De Cooman, Rein, Sara De Gieter, Roland Pepermans, Sabrina Hermans, Cindy Du Bois, Ralf Caers, and Mark Jegers. 2009. Person-organization fit: Testing socialization and attraction-selection-attrition Hypotheses. Journal of Vocational Behavior 74:102-7.

DeHart-Davis, Leisha. 2007. The unbureaucratic personality. Public Administration Review 67:892-903.

Epstein, Seymour. 1972. The Nature of Anxiety with Emphasis upon its Relationship to Ewalt, J.A.G. and Jennings, E.T. 2004, Administration, Governance, and Policy Tools in Welfare Policy Implementation. Public Administration Review 64:449-62.

Ewalt, J. A. G., and Jennings, E. T. 2004. Administration, governance, and policy tools in welfare policy implementation. Public Administration Review 64:449-62.

Folkman, Susan, and Richard S. Lazarus. 1980. An analysis of coping in a middle-aged community sample. Journal of Health and Social Behavior 21:219-39.

Gailmard, S. 2010. Politics, principal-agent problems, and public service motivation. International Public Management Journal 13:35-45.

Giauque, David, Simon Anderfuhren-Biget, and Frédéric Varone. 2012a. Stress perception in public organisations: Expanding the job demands-job resources model by including public service motivation. Review of Public Personnel Administration 33:58-83.

Giauque, David, Adrian Ritz, Frédéric Varone, and Simon Anderfuhren-Biget. 2012b. Resigned but satisfied: The negative impact of public service motivation and red tape on work satisfaction. Public Administration 90:175-83.

Gould-Williams, Julian S., Ahmed S. Mostafa, and Paul Bottomley. 2013. Public service motivation and employee outcomes in the Egyptian public sector: Testing the mediating effect of person-organization fit. Journal of Public Administration Research and Theory 25:597-622.

Graham, Jesse, Brian A. Nosek, Jonathan Haidt, Ravilyer, Spassena Koleva, and Peter H. Ditto. 2011. Mapping the moral domain. Journal of Personality and Social Psychology 101:366-85.

Greenglass, Esther R., Ralf Schwarzer, and Steffen Taubert. 1999. The Proactive Coping Inventory (PCI): A multidimensional research instrument. http:// estherg.info.yorku.ca/files/2014/09/pci.pdf (accessed September 14, 2017).

Hackett, Rick D., and Peter Bycio. 1996. An evaluation of employee absenteeism as a coping mechanism among hospital nurses. Journal of Occupational and Organizational Psychology 69:327-38.

Hamann, Darla J., and Nicole T. Foster. 2014. An exploration of job demands, job control, stress, and attitudes in public, nonprofit, and for-profit employees. Review of Public Personnel Administration 34:332-55.

Hanisch, Kathy A. 2002. The timing of thinking about quitting. In Voluntary Employee Withdrawal and in Attendance, ed. Meni Koslowsky and Moshe Krausz, 193-211. New York, NY: Springer Science + Business Media.

Hansen, Claus D., and Johan H. Andersen. 2008. Going ill to work-what personal circumstances, attitudes and work-related factors are associated with sickness presentism? Social Science \& Medicine 67:956-64.

Hassan, S., Wright, B. E., and Yukl, G. 2014. Does ethical leadership matter in government? Effects on organizational commitment, absenteeism, and willingness to report ethical problems. Public Administration Review 74:333-43.

Horton, Silvia. 2008. History and persistence of an idea and an ideal. In Motivation in public management: The call of public, ed. James L. Perry and Annie Hondeghem, 17-32. Oxford: Oxford Univ. Press.

Jehn, Karen A., Clint Chadwick, and Sherry M. Thatcher. 1997. To agree or not to agree: The effects of value congruence, individual demographic dissimilarity, and conflict on workgroup outcomes. International Journal of Conflict Management 8:287-305.

Jensen, Ulrich T., and Lotte B. Andersen. 2015. Public service motivation, user orientation, and prescription behavior: Doing good for society or for the individual user? Public Administration 93:753-68.

Jensen, Ulrich T., and C. F. Vestergaard. 2016. Public service motivation and public service behaviors: Testing the moderating effect of tenure. Journal of Public Administration Research and Theory 27:52-67.
Jin, Myung, Bruce D. McDonald, and Jaehee Park. 2016. Person-organization fit and turnover intention exploring the mediating role of employee followership and job satisfaction through conservation of resources theory. Review of Public Personnel Administration (First Published July 20, 2016).

Jones, Thomas M. 1991. Ethical decision making by individuals in organizations: An issue-contingent model. Academy of Management Review 16:366-95.

Kickert, Walter, 2012. State responses to the fiscal crisis in Britain, Germany and the Netherlands.Public Management Review 4:299-309.

Kim, Sangmook, Wouter Vandenabeele, Bradly E. Wright, Lotte B. Andersen, Francesco P. Cerase, Robert K. Christensen, Céline Desmarais, et al. 2013. Investigating the structure and meaning of public service motivation across populations: Developing an international instrument and addressing issues of measurement invariance. Journal of Public Administration Research and Theory 23:79-102.

Kinman, Gail, and Fiona Jones. 2008. Effort-reward imbalance, over-commitment and work-life conflict: Testing an expanded model. Journal of Managerial Psychology 23:236-51.

Klimecki, Olga, and Tania Singer. 2012. Empathic distress fatigue rather than compassion fatigue? Integrating findings from empathy research in psychology and social neuroscience. In Pathological altruism, ed. Barbara Oakley, Ariel Knafo, Guruprasad Madhaven, and David S. Wilson, 36883. Oxford: Oxford Univ. Press.

Koumenta, Maria. 2015. Public service motivation and organizational citizenship. Public Money \& Management 35:341-8.

Kristof, Amy L. 1996. Person-organization fit: An integrative review of its conceptualizations, measurement, and implications. Personnel Psychology 49:1-49.

Lazarus, Richard S. 1966. Psychological stress and the coping process. New York, NY: McGraw-Hill.

LePine, Jeffrey A., Nathan P. Podsakoff, and Marcie A. LePine. 2005. A metaanalytic test of the challenge stressor-hindrance stressor framework: An explanation for inconsistent relationships. Academy of Management Journal 48:725-41.

Liu, Bangcheng, Kaifeng Yang, and Wie Yu. 2015. Work-related stressors and health-related outcomes in public service: Examining the role of public service motivation. The American Review of Public Administration 45:653-73.

Loyens, Kim. 2014. Rule bending by morally disengaged detectives: An ethnographic study. Police Practice and Research 15:62-74.

Maesschalck, Jeroen, Zeger van de Wal, and Leo Huberts. 2008. Public service motivation and ethical conduct. In Motivation in public management: The call of public, ed. James L. Perry and Annie Hondeghem, 157-76. Oxford: Oxford Univ. Press.

Manning, Peter K. 1977. Police Work. Cambridge, MA: MIT Press.

Maslach, Christina, Wilmar B. Schaufeli, and Michael P. Leiter. 2001. Job Burnout. Annual Review of Psychology 52:397-422.

Maynard-Moody, Steven W., and Michael C. Musheno. 2003. Cops, teachers, counselors: Stories from the front lines of public service. Ann Arbor, MI: Univ. of Michigan Press.

McHugh, Marie, and Shirley Brennan. 1994. Managing the stress of change in the public sector. International Journal of Public Sector Management 7:29-41.

Menaghan, Elizabeth G., and Esther S. Merves. 1984. Coping with occupational problems: The limits of individual efforts. Journal of Health and Social Behavior 25:406-23.

Miller, Susanne M. 1987. Monitoring and blunting: Validation of a questionnaire to assess styles of information seeking under threat. Journal of Personality and Social Psychology 52:345-53.

Moore, Celia, James R. Detert, Linda K. Treviño, Vicki L. Baker, and David M. Mayer. 2012. Why employees do bad things: Moral disengagement and unethical organizational behavior. Personnel Psychology 65:1-48.

Netemeyer, Richard G., James S. Boles, and Robert McMurrian. 1996. Development and validation of work-family conflict and family-work conflict scales. Journal of Applied Psychology 81:400-10.

Peng, Jui-Chenhen, Yin-Ling Lee, and Mei-Man Tseng. 2014. Person-organization fit and turnover intention: Exploring the mediating effect of work engagement and the moderating effect of demand-ability fit. Journal of Nursing Research 22:1-11. 
Perry, James L., and Lois R. Wise. 1990. The motivational bases of public service. Public Administration Review 50:367-73.

Perry, James L., and Annie Hondeghem. 2008. Motivation in public management: The call of public service. Oxford: Oxford Univ. Press.

Perry, James L., and Wouter Vandenabeele. 2008. Behavioral dynamics. In Motivation in public management: The call of public, ed. James L. Perry and Annie Hondeghem, 56-79. Oxford: Oxford Univ. Press.

Petrovsky, Nicolai, and Adrian Ritz. 2014. Public service motivation and performance: A critical perspective. Evidence-based HRM: a Global Forum for Empirical Scholarship 2:57-79.

Podsakoff, Nathan P., Jeffery A. LePine, and Marcie A LePine. 2007. Differential challenge stressor-hindrance stressor relationships with job attitudes, turnover intentions, turnover, and withdrawal behavior: A metaanalysis. Journal of Applied Psychology 92:438-54.

Prebble, Mark. 2016. Has the study of public service motivation addressed the issues that motivated the study? American Review of Public Administration 46:267-91.

Punch, Maurice. 2000. Police corruption and its prevention. European Journal on Criminal Policy and Research 8:301-24.

Quratulain, Samina, and Abdul K. Khan. 2015. How does employees' public service motivation get affected? A conditional process analysis of the effects of person-job fit and work pressure. Public Personnel Management 44:266-89.

Rainey, Hal G. 1982. Reward preferences among public and private managers: In search of the service ethic. American Review of Public Administration 16:288-302.

2009. Understanding and managing public organizations, 4th ed. San Francisco, CA: Jossey-Bass.

Rainey, Hal G., and Paula J. Steinbauer. 1999. Galloping elephants: Developing elements of a theory of effective government organizations. Journal of Public Administration Research and Theory 9:1-32.

Rawls, John. 1971. A theory of justice. Cambridge: Belknap Press.

Ritz, Adrian, Gene A. Brewer, and Oliver Neumann. 2016. Public service motivation: A systematic literature review and outlook. Public Administration Review 76:414-26.

Rousseau, Denise M. 1995. Psychological contracts in organizations: Understanding written and unwritten agreements. California: Sage Publications.

Rousseau, Denise M., and McLean L. Parks. 1993. The contracts of individuals and organizations. Research in Organizational Behavior15:1-43.

Schneider, Benjamin, Brent D. Smith, Sylvester Taylor, and John Fleenor. 1998. Personality and organizations: A test of the homogeneity of personalityhypothesis. Journal of Applied Psychology 83:462-70.

Schneider, Benjamin, Harold W Goldstein, and Brent D. Smith. 1995. The ASA framework: An update. Personnel Psychology 48:747-73.

Schott, Carina, Daphne D. Van Kleef, and Mirko Noordegraaf. 2016. Confused professionals? Capacity to cope with pressures on professional work. Public Management Review18:583-610.

Schott, Carina, Daphne D. van Kleef, and Trui Steen. 2015. What does it mean and imply to be public service motivated? The American Review of Public Administration 45:689-707.
Schott, Carina, Oliver Neumann, Muriel Baertschi, and Adrian Ritz. 2017. Public service motivation, prosicial motivation, altruism, and prosocial behavior: Towards distanglement and conceptual clarity. Paper presented at the IRSPM conference, Budapest, Hungary, April 19-21.

Sen, Amartya. 2010. The idea of justice. London, UK: Penguin Classics.

Shepard, Clovis R. 1968. Small groups. San Francisco, CA: Chandler Publishing Co.

Shingler, John, Mollie E. Van Loon, Theodore R. Alter, and Jeffrey C. Bridger. 2008. The importance of subjective data for public agency performance evaluation. Public Administration Review 68:1101-11.

Shore, Lynn M., and Lois E. Tetrick. 1994. The psychological contract as an explanatory framework in the employment relationship. Journal of Organizational Behavior 1:91-109.

Steen, Trui, and Mark R. Rutgers. 2011. The double-edged sword: Public service motivation, the oath of office and the backlash of an instrumental approach. Public Management Review 13:343-61.

Stets, Jan E., and Richard T. Serpe. 2013. Identity theory. In Handbook of social psychology, 2nd ed, ed. John D. De Lamater and Amanda Ward, 31-60. New York, NY: Springer.

Stryker, Sheldon, and Peter J. Burke. 2000. The past, present, and future of an identity theory. Social Psychology Quarterly 63:284-97.

Tetrick, Lois E., and James M. LaRocco. 1987. Understanding, prediction, and control as moderators of the relationships between perceived stress, satisfaction, and psychological well-being. Journal of Applied Psychology 72:538-43.

Tummers, Lars, Ulrike Weske, Robin Bouwman, and Stephan Grimmelikhuijsen. 2016. The impact of red tape on citizen satisfaction: An experimental study. International Public Management Journal 19:320-41.

Tummers, Lars, Viktor Bekkers, Evelin Vink, and Michael Musheno. 2015. Coping during public service delivery: A conceptualization and systematic review of the literature. Journal of Public Administration Research and Theory 25:1099-126.

Vandenabeele, Wouter. 2007. Toward a public administration theory of public service motivation: An institutional approach. Public Management Review 9:545-56.

Van Loon, Nina M., Wouter Vandenabeele, and Peter Leisink. 2015. On the bright and dark side of public service motivation: The relationship between PSM and employee wellbeing. Public Money \& Management 35:349-56.

Van Knippenberg Daan, Carsten K. W. De Dreu, and Astrid C. Homan. 2004. Work group diversity and group performance: An integrative model and research agenda. Journal of Applied Psychology 89:1008-22.

Wouters, Kristel, Jeroen Maesschalck, Carel F. Peeters, and Marijke Roosen. 2014. Methodological issues in the design of online surveys for measuring unethical work behavior: Recommendations on the basis of a split-ballot experiment. Journal of Business Ethics 120:275-89.

Wright, Bradly E., and Adam M. Grant. 2010. Unanswered questions about public service motivation: Designing research to address key issues of emergence and effects. Public Administration Review 70:691-700.

Zhao, Hho, Sandy J. Wayne, Brian C. Glibkowski, and Jesus Bravo. 2007. The impact of psychological contract reach on work-related outcomes: A meta-analysis. Personnel Psychology 60:647-80. 